\title{
A novel spontaneous hepatocellular carcinoma mouse model for studying T-cell exhaustion in the tumor microenvironment
}

\author{
Yu-Tzu Liu ${ }^{1 \dagger}$, Tai-Chung Tseng ${ }^{2,3+}$, Ruey-Shyang Soong ${ }^{4,5 \dagger}$, Chun-Yi Peng ${ }^{1}$, Yu-Hsing Cheng ${ }^{1}$, Shiu-Feng Huang ${ }^{1}$, \\ Tsung-Hsien Chuang ${ }^{6}$, Jia-Horng Kao ${ }^{2,3,7,8}$ and Li-Rung Huang ${ }^{1,7^{*}}$ (D)
}

\begin{abstract}
Immunotherapy has ushered in a new era of cancer therapy, and this is also applicable to therapy of hepatocellular carcinoma (HCC). In this context, effective development of therapeutic strategies requires an HCC mouse model with known tumor-associated antigens (TAAs) and an HCC growth reporter. We created such a model using hydrodynamic injection and a transposon system to introduce AKT and NRAS and open reading frames (ORFs) encoding surrogate tumor antigens and luciferase into chromosomes of hepatocytes to induce nodular and diffuse tumors in the liver. TAAspecific CD8 ${ }^{+} \mathrm{T}$ cells were detected during HCC progression; however, these showed exhausted-like phenotypes and were unable to control tumor growth. Myeloid-derived suppressor cells (MDSCs) and tumor-associated macrophages (TAM) from the tumor microenvironment were found to contribute to the suppression of the CD $8^{+} \mathrm{T}$-cell response. The transposon-based Akt/N-Ras-induced HCC mouse model we developed enables researchers to monitor tumor growth non-invasively and to quantify and characterize endogenous or adoptively transferred TAA-specific CD8 ${ }^{+} \mathrm{T}$-cell responses. These features make it a suitable preclinical model for exploration and evaluation of immune checkpoint inhibitors and cell-based immunotherapies for HCC treatment.
\end{abstract}

Keywords: Hepatocellular carcinoma, T-cell exhaustion, Tumor-associated macrophage, MDSC, Tumor-specific T cell, Immune checkpoint, Immunotherapy

\section{Background}

Hepatocellular carcinoma $(\mathrm{HCC})$ is the second leading cause of cancer deaths worldwide. HCC responds poorly to chemotherapies or targeted therapies and therefore developing new therapeutic strategies for HCC treatment, especially immunotherapies, is now on the rise [1]. The breadth of tumor-associated antigen (TAA)-specific $\mathrm{CD}^{+}{ }^{+} \mathrm{T}$-cell responses has been found to be positively correlated with HCC patient survival [2]. Therefore, immunotherapies for treatment of malignancies e.g. immune checkpoint inhibitors or adoptive T-cell therapy aim to restore TAA-specific T-cell responses. A suitable immunocompetent HCC

\footnotetext{
* Correspondence: Irhuang@nhri.org.tw

${ }^{\dagger}$ Yu-Tzu Liu, Tai-Chung Tseng and Ruey-Shyang Soong contributed equally to this work.

'Institute of Molecular and Genomic Medicine, National Health Research Institutes, No.35, Keyan Road, Zhunan Town, Miaoli County 350, Taiwan ${ }^{7}$ Graduate Institute of Clinical Medicine, National Taiwan University, Taipei, Taiwan

Full list of author information is available at the end of the article
}

mouse model for studies on HCC tumor immunology and immunotherapy development is urgently needed. There are various experimentally induced liver tumor mouse models including chemically induced models, implantation models (syngeneic and xenograft model) and genetically engineered models (GEM) [3, 4]. The immunocompromised xenograft HCC models are not ideal for use in immunological studies, whereas humanized mice with a functional human immune system may address this drawback. Although syngeneic HCC implants can grow in immunocompetent mice, the initial immune response in the tumor microenvironment (TME) may not mimic that arising from spontaneous HCC. Most of the chemically induced models or GEM require a long period of time to develop tumors and it can be challenging to monitor tumor growth in such mice.

Hydrodynamic injection (HDI), designed to deliver naked DNA into hepatocytes, is widely used in studies of liver diseases including persistent HBV infection and 
HCC $[5,6]$. Combining HDI and a transposon system to deliver oncogenes could facilitate transfection and transformation of hepatocytes, making the technique perfect for establishment of various kinds of HCC models and to examine the oncogenic potential of specific genes in liver cancers. The advantage of HDI-based HCC mouse models over GEMs is their flexibility in terms of transgenes and strains of the recipient mice, reducing cost and time. Neuroblastoma Ras viral oncogene homologs (Nras, NRasV12), shP53, myr-AKT, c-Myc, $\Delta N 90-\beta$-catenin, $\mathrm{c}-$ Met and other oncogenes or viral genes have been used to establish HDI-based HCC models [6]. The time requirement for HCC growth in these HDI-based models is much less than other viral gene-transgenic $(\mathrm{tg})$ mouse models e.g. HBx, HBs models.

Delivery of activated forms of $A K T$ and Nras via a transposon system into mouse hepatocytes has been shown to induce rapid HCC growth in FVB/N mice [7]. Although activating Ras mutations are seldom found in human HCC samples, simultaneous activation of Akt/ mTOR and Ras/MAPK pathways is often found in human HCC [8]. Previous studies examining the potential and roles of $A K T$ and $R A S$ in HCC induction have shown that activated $A K T$ alone required nearly 30 weeks to induce $\mathrm{HCC}$ formation [9] whereas activated RAS alone was not able to induce HCC formation but caused hepatocyte senescence in immunocompetent mice [10]. The Akt/mTOR pathway involves in lipogenesis, which also promotes the development of $\operatorname{HCC}[9,11]$. We therefore adopted the Akt/N-Ras-based HDI technology [7] to establish a novel HCC mouse model expressing luciferase and surrogate tumor antigens (Ags) to monitor tumor growth non-invasively. Tumor progression in this HCC model was found to be more rapid than that in most of the chemically induced and genetically modified models. Both diffuse and nodular types of HCC were observed to develop in this model. We were able to characterize the exhausted state of TAA-specific $\mathrm{CD}^{+} \mathrm{T}$ cells and immunosuppressive cell populations in the TME in the model, indicating that it can be a suitable preclinical model for exploration and evaluation of immune checkpoint inhibitors and cell-based immunotherapies for HCC treatment.

\section{Methods}

\section{Animal studies and hydrodynamic injection}

Male C57BL/6j mice at the age of 4-5 week-old were purchased from the National Laboratory Animal Center (Taipei, Taiwan) and were kept in laboratory animal cen-

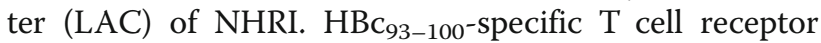
(TCR) tg mice [12] were kindly provided by Dr. Francis V. Chisari and Dr. Masanori Isogawa (The Scripps Institute, La Jolla, USA) and were kept in LAC of NHRI. The two animal facilities are accredited by Association for
Assessment and Accreditation of Laboratory Animal Care International (AAALAC International). C57BL/6j mice were anesthetized by Isoflurane mixed with $\mathrm{O}_{2}$ before HDI and given HDI of endotoxin-free plasmids dissolved in filtered Dulbecco Phosphate Buffered Saline (DPBS) in a volume equivalent to $8 \%$ body weight within $5 \mathrm{~s}$. For the mice receiving $2 \mu \mathrm{g}$ of $\mathrm{pCMV}(\mathrm{CAT}) \mathrm{T} 7-\mathrm{SB} 100,10 \mu \mathrm{g}$ of pT/Caggs-NRASV12 and $10 \mu \mathrm{g}$ of pKT2/CLP-AKT-LUC or pKT2/CLP-AKT-2A-OVA-HBc-HBs-LUC plasmids, the photons emitted from the transduced hepatocytes or tumor cells within the live animals were detected and quantified periodically using IVIS imaging system (Caliper Life Sciences, Massachusetts, USA). The mice were injected intraperitoneally with $3 \mathrm{mg}$ of D-luciferin (Biosynth Chemistry \& Biology, Staad, Switzerland) and waited for $10 \mathrm{~min}$ before being imaged under anesthesia by isoflurane inhalation. HCC-bearing mice with the total flux from IVIS imaging above $3 \times 10^{10}$ photons/sec were subjected to human sacrifice to avoid the suffering of mice from large liver tumors.

\section{Construction and plasmid preparation}

pCMV(CAT)T7-SB100 [13] was a gift from Zsuzsanna Izsvak (Addgene plasmid \#34879). pKT2/CLP-AKT and pT/Caggs-NRASV12 [14] were gifts from John Ohlfest (Addgene plasmids \#20281 \& \#20205). The ORF of firefly luciferase was amplified from pLAS5W-Luc-2A-eGFP [15] by PCR and sub-cloned into 3 ' end of human $A K T 1$ of $\mathrm{pKT} 2 / \mathrm{CLP}-\mathrm{AKT}$ with $\mathrm{p} 2 \mathrm{~A}$ peptide sequence between the two ORFs to result in pKT2/CLP-AKT-LUC plasmid. The expression cassette was flanked by $5^{\prime}$ and 3' transposon inverted repeats (IRs). A mini-gene encoding polypeptides derived from ovalbumin (OVA), core protein $(\mathrm{HBcAg})$ and surface protein ( $\mathrm{HBsAg}$ ) of hepatitis B virus was synthesized (PURIGO Biotechnology, Taipei, Taiwan) and sub-cloned into pKT2/CLP-AKT-LUC to result in pKT2/CLP-AKT-OVA-HBcHBs(Ags)-LUC plasmid. The DNA and polypeptide sequences of the mini-gene were listed in Fig. 1a. All the plasmids were amplified in DH5 $\alpha$ E.coli and purified using QIAGEN EndoFree plasmid kits (Qiagen, Hilden, Germany).

\section{Immunohistochemistry study}

Paraffin-embedded liver/tumor tissue sections were deparaffinized, rehydrated, followed by heat-induced antigen retrieval and then incubated with primary antibodies as listed in Additional file 1: Table S1. ImmPRESS anti-Rat Ig, ImmPRESS anti-Rabbit Ig, Mouse adsorbed (peroxidase) Polymer Detection Kit, DAB Peroxidase Substrate Kit and Hematoxylin (all from Vector laboratories, Burlingame, USA) were used for detection and visualization. For detection of CD45.1 $1^{+}$adoptively transferred $\mathrm{CD}^{+} \mathrm{T}$ cells, $5-7 \mu \mathrm{m}$ of liver/tumor tissue frozen sections were fixed 


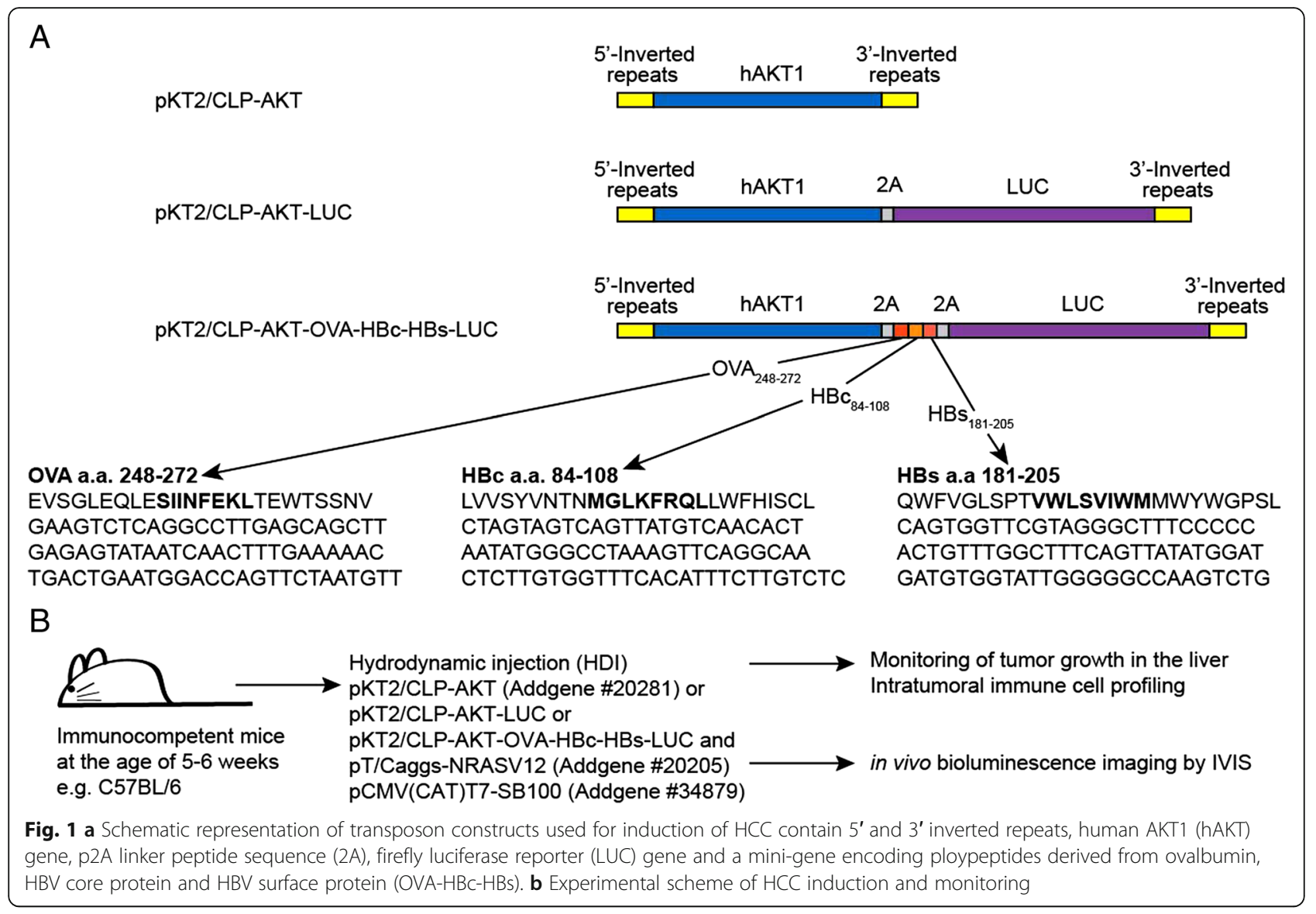

in ice cold acetone/chloroform (1:1), incubated with FITC-conjugated anti-CD45.1 (A20, Biolegend) and anti-FITC conjugate HRP (Thermo Fisher Scientific, Waltham, USA), followed by incubation with DAB substrate. For detection of lipid droplets, 5-7 $\mu \mathrm{m}$ liver/ tumor tissue frozen sections were fixed in $10 \%$ formalin, incubated with oil red $\mathrm{O}$ dye for $15 \mathrm{~min}$ and washed with $60 \%$ isopropanol to remove the excess dye before mounting with glycerol jelly mounting medium. The images were captured using an automatic digital slide scanner Pannoramic MIDI with Plan-Apochromat 20x/ 0.8 objective (3D HISTECH) by Pathology Core Laboratory of NHRI and have been evaluated by an experienced pathologist (SFH).

\section{T-cell preparation and adoptive transfer}

Splenic $\mathrm{CD}^{+} \mathrm{T}$ cells from CD45.1 $1^{+} \mathrm{HBC}_{93-100}$-specific TCR tg mice were isolated by immunomagnetic separation using CD8 microbeads (StemCell Technologies, Vancouver, Canada). Purified $\mathrm{CD}^{+} \mathrm{T}$ cells were stimulated for 3 days with anti-CD3/CD28 labeled T-activator Dynabeads $^{\circ}$ (Thermo Fisher Scientific) in RPMI 1640 medium (Thermo Fisher Scientific) supplemented with $8 \%$ FCS, $50 \mu \mathrm{M}$ 2-mercaptoethanol, glutamine and antibiotics. After magnetic removal of Dynabeads, living cells were separated from dead cells using Ficoll-Paque plus density gradient media (GE healthcare Life Sciences, Illinois, USA). $2-3 \times 10^{5}$ activated $\mathrm{CD}^{+} \mathrm{T}$ cells were adoptively transferred into HCC-bearing mice $\left(\mathrm{CD} 45.2^{+}\right)$with total flux ranging from $1 \times 10^{8}$ to $5 \times 10^{9}$ photons/sec. The mice receiving adoptive transfer of $\mathrm{HBC}_{93-100}$-specific CTLs were given anti-mouse PD-1 Ab (clone: RMP1-14, Bio X cell, New Hampshire, USA) and isotype control Ab (clone: 2A3, Bio X cell), respectively, at the dose of $10 \mu \mathrm{g} / \mathrm{gram}$ body weight via intraperitoneal injection every 3 days for 6 times. The adoptively transferred $\mathrm{CD} 8^{+} \mathrm{T}$ cells could be visualized using a fluorescently labeled anti-CD45.1 antibody followed by flow cytometric analysis or immunohistochemical staining.

\section{Cell isolation and flow cytometry analysis}

Livers were perfused via the portal vein with a $50 \mu \mathrm{g} / \mathrm{ml}$ collagenase IV solution (Sigma-Aldrich, St. Louis, USA), mechanically disrupted, and digested for $20 \mathrm{~min}$ at $37^{\circ} \mathrm{C}$ in Gey's balanced salt solution (GBSS) with $50 \mu \mathrm{g} / \mathrm{ml}$ collagenase IV, then filtered through a $250-\mu \mathrm{m}$ cell strainer. Cells were re-suspended in $10 \mathrm{~mL}$ DPBS and underlaid with $5 \mathrm{~mL}$ of Ficoll-Paque plus density gradient media for gradient centrifugation for $10 \mathrm{~min}$ at 2000 
rpm at $4{ }^{\circ} \mathrm{C}$. After centrifugation, leukocytes were collected from the interface and subjected to flow cytometric analysis or FACSorting.

All stainings for flow cytometric analysis were performed in the presence of $10 \mu \mathrm{g} / \mathrm{mL}$ of Fc block (2.4G2) in fluorescence-activated cell sorting buffer (FACS buffer, phosphate-buffered saline/2\% bovine serum albumin/ $0.02 \% \mathrm{NaN}_{3}$ ). Acquisition and data analysis were conducted on Attune NxT flow cytometer (Thermo Fisher Scientific) and FlowJo software (V.10.0.8r1, FlowJo, LLC, Ashland, USA). Antibodies and dye used for flow cytometric analysis were listed in Additional file 1: Table S2. APC-conjugated dextramers recognizing $\mathrm{H}-2 \mathrm{k}^{\mathrm{b}}$-restricted TCRs specific for

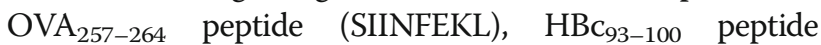
(MGLKFRQL) and $\mathrm{HBs}_{190-197}$ peptide (VWLSVIWM), respectively were purchased from Immudex (Copenhagen, Denmark). The cell number of specific cell populations in tumor and liver were adjusted to weight and expressed as $\times 10^{6}$ or $\times 10^{3} / \mathrm{gram}$. The tumor-associated macrophages (TAMs) $\left(\mathrm{CD} 146^{-} \mathrm{CD} 11 \mathrm{~b}^{+} \mathrm{F} 4 / 80^{+} \mathrm{MHC} \mathrm{II}\right)$ and myeloid-derived suppressor cells (MDSCs) $\left(\mathrm{CD} 146^{-} \mathrm{CD} 11 \mathrm{~b}^{+} \mathrm{Gr}-1^{+} \mathrm{MHC} \mathrm{II}^{-}\right)$from liver tumors of HCC-bearing mice and macrophages $\left(\mathrm{CD}_{11 \mathrm{~b}^{+} \mathrm{F} 4 /}\right.$ $\left.80^{+} \mathrm{MHC} \mathrm{II}\right)$ and $\mathrm{Gr}-1^{+}$cells $\left(\mathrm{CD} 11 \mathrm{~b}^{+} \mathrm{Gr}-1^{+} \mathrm{MHC} \mathrm{II}\right)$ from spleens of normal C57BL/6j mice were isolated from tumor-associated leukocytes or splenocytes through FACSorting using Influx (BD Biosciences, San Jose, CA, USA).

\section{In vitro T-cell suppression assay}

$8 \times 10^{4}$ anti-CD3/anti-CD28 beads activated $\mathrm{HBC}_{93-100}$-specific $\mathrm{CD}^{+} \mathrm{T}$ cells were re-stimulated by anti-CD3/ anti-CD28 beads and were co-cultured with various numbers of FACSorted TAMs or MDSCs for $24 \mathrm{~h}$. The proliferation of $\mathrm{CD}^{+} \mathrm{T}$ cells was measured by incorporation of 5-Ethynyl-2'-deoxyuridine (EdU), a thymidine analog. EdU $(4 \mu \mathrm{M})$ was added at $6 \mathrm{~h}$ prior harvest of cells. EdU staining was performed using Click-iT EdU Alexa Fluor 488 Flow Cytometry Kit (Thermo Fisher Scientific).

\section{Statistic analysis}

GraphPad Prism 7 (GraphPad Software, La Jolla, USA) and Student's $t$-test were used for statistical analysis.

\section{Results}

\section{Myristoylated (Myr)-Akt1 and N-Ras work synergistically} to induce hepatocellular carcinoma in immunocompetent mice

We amplified and inserted a DNA fragment encoding the firefly luciferase reporter gene into the pKT2/ CLP-AKT plasmid to result in the pKT2/CLP-AKT-LUC plasmid (Fig. 1a). Mini-gene encoded polypeptides derived from OVA (a.a. 248-272), and hepatitis B core (a.a. 84-108) and envelope (a.a. 181-205) proteins were synthesized and inserted into the pKT2/CLP-AKT-LUC plasmid to result in the pKT2/CLP-AKT-OVA-HBc-HBsLUC plasmid (Fig. 1a). The amino acids in bold in each polypeptide are epitopes presented by $\mathrm{MHC}$ class $\mathrm{I}-\mathrm{K}^{\mathrm{b}}$. The epitopes SIINFEKL and MGLKFRQL could be recognized by TCRs of OT-I tg mice and $\mathrm{HBc}_{93-100}$ TCR tg mice, respectively (Fig. 1a).

We first examined the capability and kinetics of activated Akt and N-Ras in HCC induction in C57BL/6 mice (Fig. 1b). We started to observe pinpointed white spots on the liver of a few injected C57BL/6j mice at day 30 post HDI with the three plasmids encoding myr-Akt1, N-RasV12, and sleeping beauty transposase. These pinpointed white spots on the liver were observed in nearly all of the injected mice by day 45 (Fig. 2a, yellow arrow). Some livers at day 45 and day 58, and all the livers by day 75 were covered with small nodules (Fig. 2a and data not shown). Histological examination of the liver tissues at day 30 post HDI revealed that most of the liver tissues were still normal except for the appearance of clusters of adipocyte-like cells in certain areas of the liver (Fig. 2b, c, yellow arrow). Eighty percent and $100 \%$ of the injected mice at day 45 and day 58 post $\mathrm{HDI}$, respectively, had already developed HCC in the liver. Cytoplasmic basophilia and a high nuclear-tocytoplasmic ratio were observed in cancer cells in tumor nodules. Fatty changes and ballooning changes of the tumor cells were abundant in the tumor tissues (Fig. 2d, e). Moreover, the tumor tissues had abundant mononuclear cells infiltrations and increased stroma cells especially at the edge of the tumor nodules (Fig. 2e, yellow arrow).

\section{Cellular composition in fatty change regions and late} tumor tissues of the Akt1/N-Ras-induced HCC mouse model This spontaneous HCC model provided a good opportunity to reveal early immunologically cellular events during HCC progression. Activation of the Akt pathway can induce lipogenesis in hepatocytes, which subsequently induces carcinogenesis [9]. Marked lipid accumulation in the liver tissue from mice at day 30 or 45 , and in tumor tissue at day 58 was confirmed via oil-red staining (Fig. 3a). We then profiled immune cells in early tissues with fatty changes and in late tumor tissues after HCC induction and observed that the majority of the immune cells attracted to the fatty change tissue were $\mathrm{F} 4 /$ $80^{+}$macrophages rather than Gr-1 $1^{+}$MDSCs (Fig. 3b, c). The infiltration of MDSCs increased in both the peritumoral and tumoral regions during HCC development (Fig. 3c, day 58). In the fatty change tissues, the major proliferative cells were mononuclear cells, most likely to be immune cells, but not hepatocytes; however, there were many Ki-67-positive cancer cells detected in the tumor region at day 58 after HCC induction (Fig. 3d). 
A

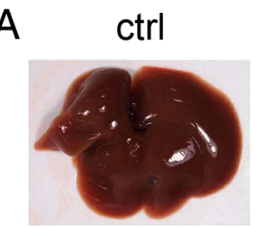

d30

d45

d58

d75

B
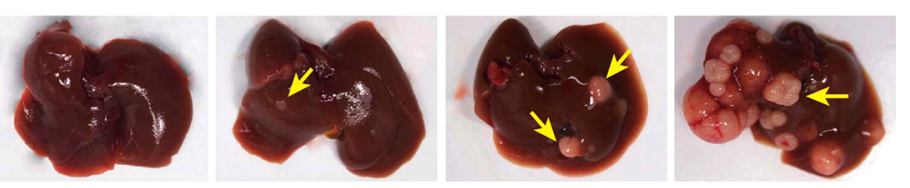

C

HDI day 30

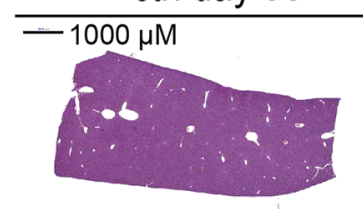

$=1000 \mu \mathrm{M}$

$=1000 \mu \mathrm{M}$
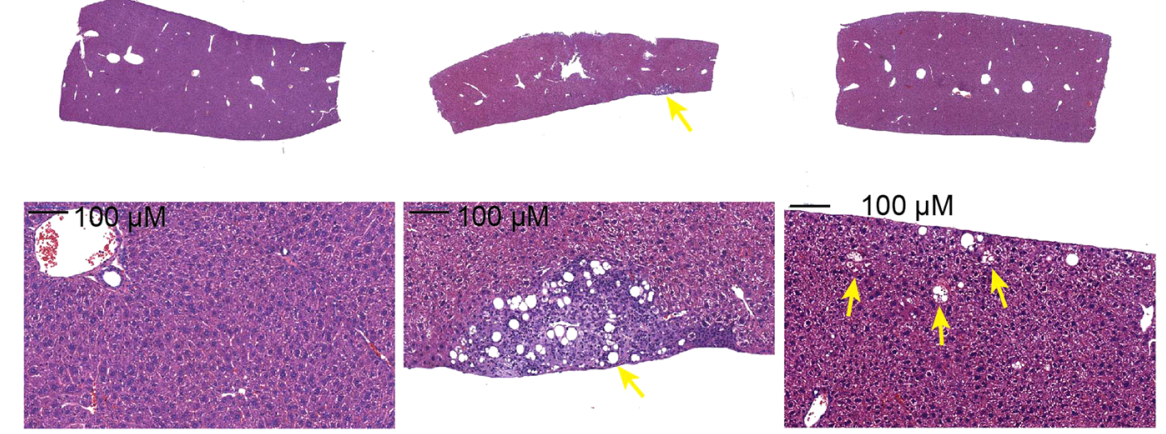

$\mathrm{D}$

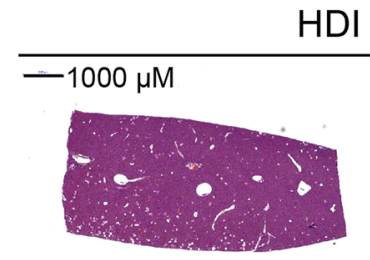

day 45

E

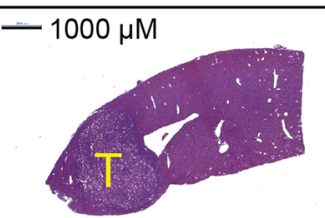

HDI day 58
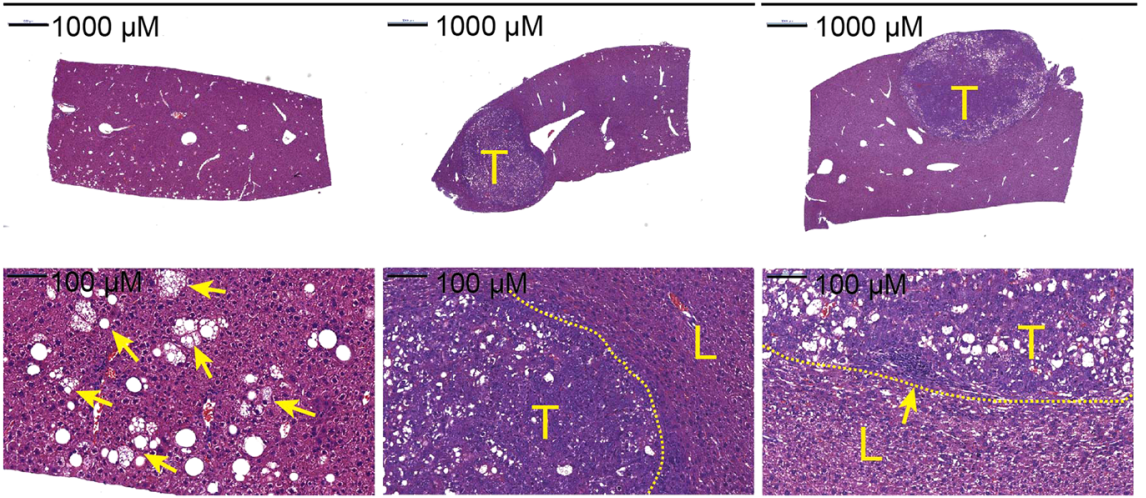

Fig. 2 Kinetics of HCC induction in mice receiving HDI of pKT2/CLP-AKT, pT/Caggs-NRASV12 and pCMV(CAT)T7-SB100. a Livers harvested from the mice at indicated time points after HDI. Yellow arrows indicate white spots or nodules on the liver. Hematoxylin-and-eosin (H\&E) staining of liver sections from $\mathbf{b}$ mice at day 58 post HDI with DPBS (ctrl), c mice at day 30, d mice at day 45, or e mice at day 58 post HDI with DPBS containing the three plasmids. Yellow arrows in (c) and (d) indicated fatty change regions. The yellow arrow in $\mathbf{e}$ indicated mononuclear infiltration near the stroma; T: tumor region, L: adjacent liver tissue; Scale bars, 1000 or $100 \mu \mathrm{m}$

We detected clustered $\mathrm{CD} 4^{+} \mathrm{T}$ cells, $\mathrm{CD} 19^{+} \mathrm{B}$ cells, and scattered $\mathrm{CD}^{+} \mathrm{T}$ cells in the fatty change tissues and late tumor tissues (see Additional file 2: Figure S1A-C). A few myofibroblasts expressing alpha-smooth muscle actin $(\alpha-\mathrm{SMA})$ were found in the fatty change tissues and they also accumulated in late tumor tissues; they were especially abundant in the peritumoral region (see Additional file 2: Figure S1D). $\mathrm{CD} 31^{+}$endothelial cells were not abundant in fatty change tissues but increased during HCC progression. The blood vessels in the tumor region showed irregularity and abnormality in morphology (see Additional file 2: Figure S1E). Our data suggest that during the onset of steatosis-related HCC, immune cells, especially macrophages and lymphocytes, infiltrated the fatty change tissues, which probably contributed to the later establishment of tumoral vasculature and proliferation of cancer stem cells. Moreover, the appearance of clustered $\mathrm{CD} 4^{+}$ and $\mathrm{CD} 19^{+} \mathrm{B}$ cells in the stroma surrounding the tumor region suggests the emergence of ectopic lymphoid structures (ELSs) during HCC development in this model, similar to the findings in human HCC specimens and other HCC mouse models [16].

\section{Characterization of the Akt1/N-Ras-induced HCC mouse model with expression of luciferase and surrogate Ags}

We then examined the tumor growth and luciferase expression in C57BL/6 mice receiving HDI with the plasmids pKT2/CLP-AKT-OVA-HBc-HBs-LUC, pT/ 


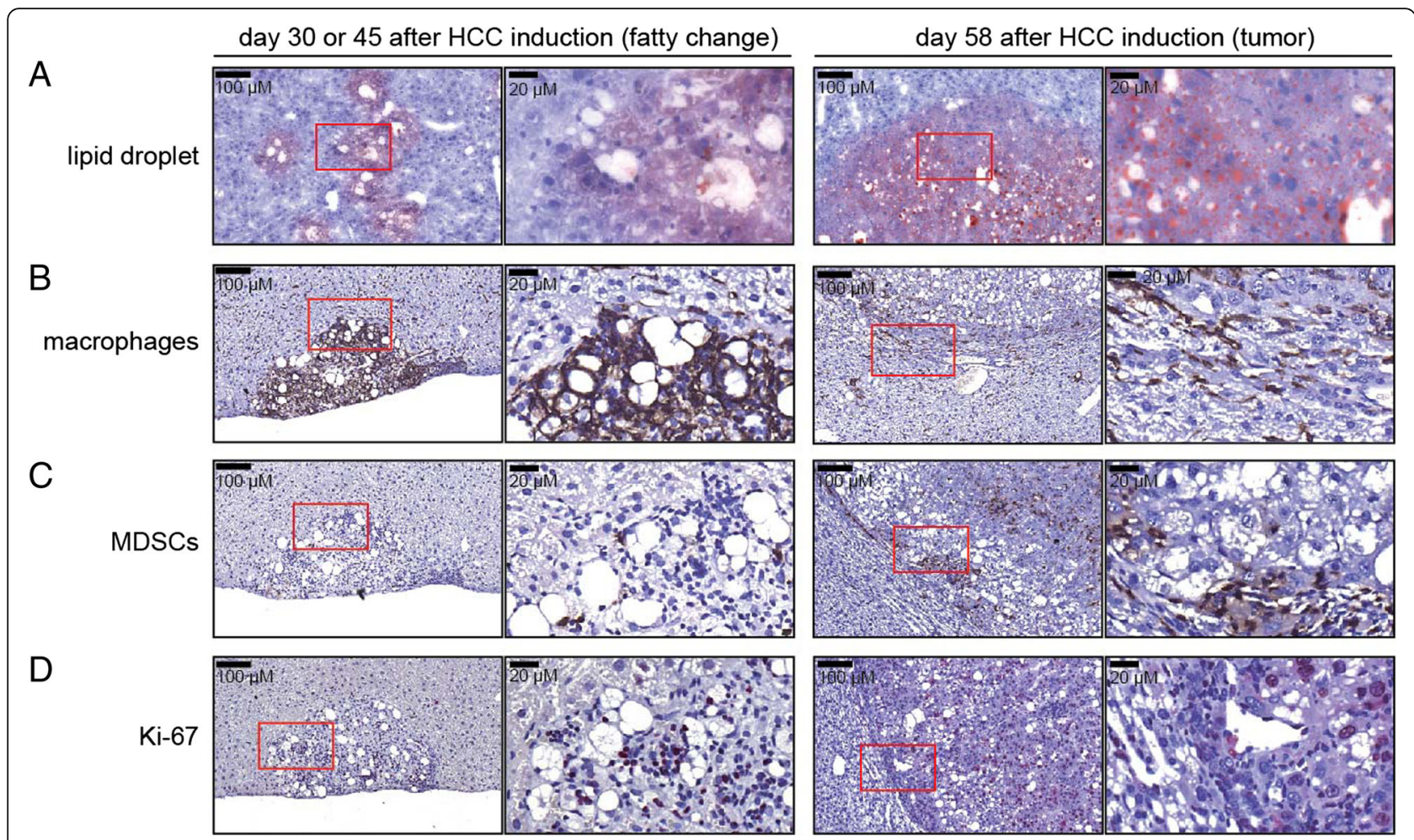

Fig. $3 \mathrm{Imm}$ unohistochemical analysis of indicated proteins in the liver or tumor tissues of mice from Fig. 2. Tissues were collected at day 30 or 45 (fatty change) or day 58 (tumor) post HDI. a Oil red O, b F4/80, c Gr-1, and d Ki-67 staining of the liver/tumor tissues were shown. Scale bars, 100 or $20 \mu \mathrm{m}$

Caggs-NRASV12, and pCMV(CAT)T7-SB100 and found two different patterns of tumor growth in the injected mice. We expected that after HDI, the plasmids would transiently exist in hepatocytes as episomal forms and we did observe moderate luciferase activity in the first week after HDI (Fig. 4a). We then observed a decline in luciferase activity in these injected mice from the 1st week to the 5th week, probably due to the clearance of some hepatocytes harboring plasmids due to immune responses. An increase in luciferase activity was observed from the 5th week onwards and reached $10^{10}$ photons/ second by the 7th week (Fig. 4a). The increase in luciferase activity is a reflection of tumor growth, resulting from transformation of the hepatocytes due to integration of ORFs of AKT-OVA-HBc-HBs-LUC and NRASV12. Interestingly, we observed that $1 / 3$ of the mice receiving the three plasmids did not undergo the decline phase and their luciferase activity increased rapidly, reaching $10^{10}$ photons/second at the 3rd week (Fig. 4a). The liver of mice showing a rapid increase in luciferase looked pale and rough (Fig. 4b, middle panel), and appeared to be occupied by diffuse tumor infiltrations. The average weight of the liver with diffuse tumors was $3.968 \pm 0.5721 \mathrm{~g}$ whereas that of the liver with nodular tumors was $1.823 \pm 0.1531 \mathrm{~g}$ in the 6 th week after induction. Histological examination revealed that the nodular tumors had clear boundaries between tumor and adjacent liver tissues, whereas the diffuse tumors invaded the normal liver tissues without a clear boundary between each other (Fig. 4c, d). We then measured the weight of the nodular tumors from each tumor-bearing mouse and correlated them with the total flux of the mice before being sacrificed, as measured using IVIS, and found a strong correlation between tumor weight and the luciferase activity. However, the correlation was lower when the total flux was higher than $10^{10}$ photons/ seconds (Fig. 4e). Marked fatty change with a high level of lipid accumulation in the tissues of diffuse infiltrating tumors was observed and there were a lot of Ki-67-positive cells detected in the tumor tissues. Macrophages, MDSCs, and activated myofibroblasts were also abundant in the diffuse infiltrating tumors (Fig. 4f). There were CD31 ${ }^{+}$ cells detected in the diffuse infiltrating tumors but less abundant in comparison with nodular tumors (Fig. 4f). Lymphocytes including $\mathrm{CD}^{+}$and $\mathrm{CD}^{+} \mathrm{T}$ cells and $\mathrm{CD} 19^{+} \mathrm{B}$ cells were also detected in the diffuse infiltrating tumors; however, they were scattered rather than clustered in the tumor tissues, differing from those in nodular tumors (Fig. 4f).

\section{Existence of TAA-specific $\mathrm{CDB}^{+} \mathrm{T}$ cells in the Akt1/N-Ras- induced HCC mouse model}

A $\mathrm{CD}^{+}$T-cell response is critical for a HCC mouse model to be useful in drug screening and evaluation of 


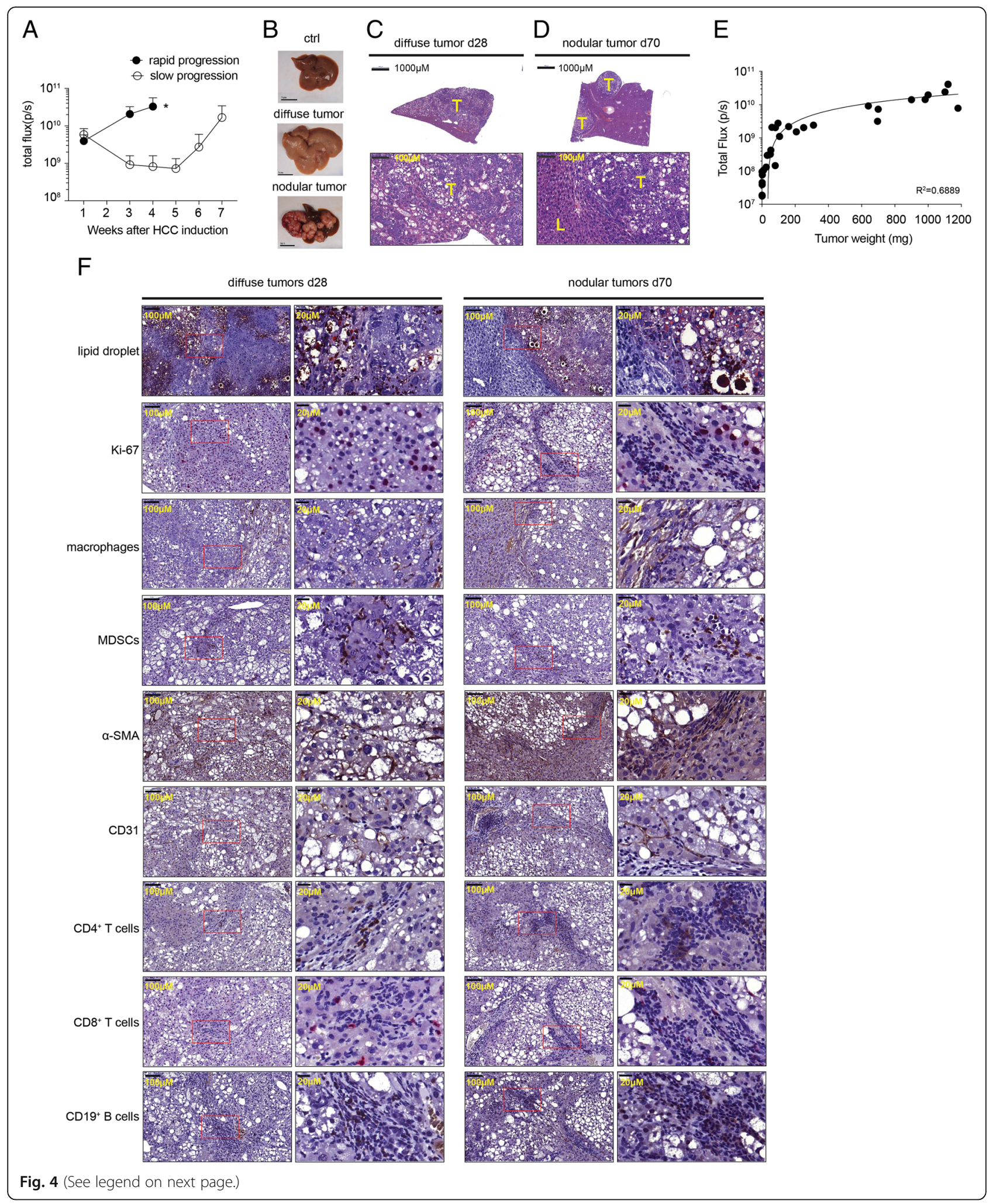


(See figure on previous page.)

Fig. 4 Both diffuse and nodular tumors were induced in C57BL/6j mice by HDI with pKT2/CLP-AKT-Ags-LUC, pT/Caggs-NRASV12 and pCMV(CAT)T7SB100. a Bioluminescence of mice at indicated time points post HDI. Two different patterns, rapid and slow progression, of bioluminescence activity were shown. *The humane endpoint for tumor-bearing mice. $\mathbf{b}$ Representative livers harvested from the mice with rapid progression (d28) or slow progression (d70) after HDI. H\&E staining of $\mathbf{c}$ the liver section from a representative mouse developing diffuse liver tumors at day 28 post HDI and $\mathbf{d}$ the liver section from one representative mouse developing nodular liver tumors at day 70 post HDI. T: tumor region, L: adjacent liver tissue; Scale bars, 1000 or $100 \mu \mathrm{m}$. e The correlation of the size of nodular tumors and their bioluminescence by IVIS ( $n=29)$. f Staining of lipid, Ki-67, F4/80, Gr-1, a-SMA, CD31, CD4, CD8, CD19 of the diffuse and nodular tumor tissues were shown. Scale bars, 100 or $20 \mu \mathrm{m}$

therapeutic strategies, because $\mathrm{CD}^{+}{ }^{+} \mathrm{T}$ cells are critical to tumor growth suppression and prevention of tumor recurrence. We collected tumor infiltrating leukocytes (TILs) from tumor tissues of mice receiving HDI with plasmids encoding AKT-OVA-HBc-HBs-LUC, NRASV12, and transposase, or receiving plasmids encoding AKT-LUC, NRASV12, and transposase. We then quantified the number of $\mathrm{HBC}_{93-100^{-}}$, HBs-190-197-, and $\mathrm{OVA}_{257-264^{-}}$-specific $\mathrm{CD}^{+} \mathrm{T}$ cells using flow cytometric analysis. All popula-

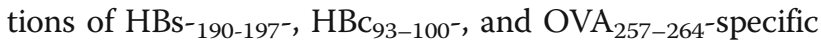
$\mathrm{CD}^{+}{ }^{+} \mathrm{T}$ cells were detected in the tumors of mice receiving the AKT-OVA-HBc-HBs-LUC plasmid $\left(\mathrm{Ag}^{+}\right)$but not in the tumors of mice receiving the AKT-LUC plasmid $\left(\mathrm{Ag}^{-}\right)$(Fig. 5a-c, see Additional file 3: Figure S2A-B), indicating the expression of these surrogate tumor Ags in the cancer cells. However, the appearance of TAA-specific $\mathrm{CD}^{+} \mathrm{T}$ cells did not control tumor growth and more than $90 \%$ of the injected mice developed HCC (Fig. 4a). We therefore analyzed the status of T-cell exhaustion of these TAA-specific $\mathrm{CD}^{+} \mathrm{T}$ cells and found that intratu-

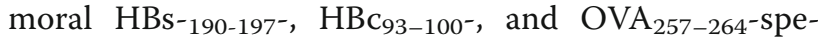
cific $\mathrm{CD}^{+} \mathrm{T}$ cells expressed relatively high levels of PD-1, LAG-3, 2B4, and TIGIT on their surface in comparison with those on total splenic $\mathrm{CD}^{+} \mathrm{T}$ cells

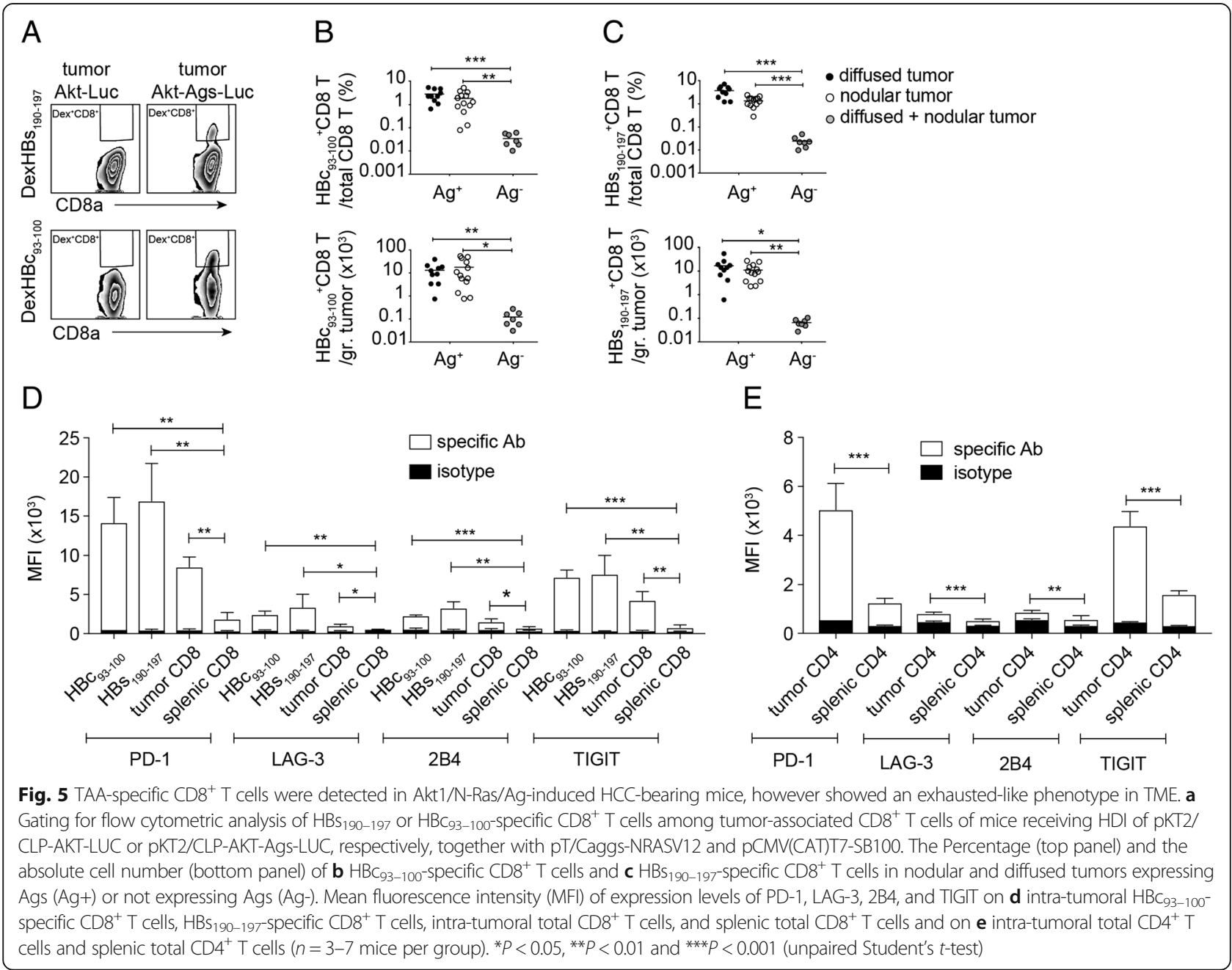


(Fig. 5d, see Additional file 3: Figure S2C). High percentages of the TAA-specific CTLs expressed these immune checkpoints (see Additional file 3: Figure S2D-G, see Additional file 4: Figure S3A-D). The total intratumoral $\mathrm{CD}^{+} \mathrm{T}$ and $\mathrm{CD} 4^{+} \mathrm{T}$ cells also expressed higher levels of immune checkpoints on their surface when compared with total splenic $\mathrm{CD} 8^{+}$and $\mathrm{CD} 4^{+} \mathrm{T}$ cells, suggesting that the TME induces T-cell exhaustion (Fig. 5d, e, see Additional file 4: Figure S3A-H). Most of the intratumoral PD- $1^{\text {hi }} \mathrm{CD}^{+}$and PD- ${ }^{\text {hi }}{ }^{\mathrm{CD}} 8^{+} \mathrm{T}$ cells proliferated less and failed to produce cytokines in comparison with the $\mathrm{PD}-1^{\text {low/- }}$ cell population in response to in-vitro plate-bound anti-CD3/anti-CD28 re-stimulation (see Additional file 5: Figure S4A-E). These data clearly demonstrated that tumor-specific CTLs were indeed induced during HCC development; however, the Akt1/N-Ras induced HCC model showed strong immunosuppression in the TME and drove dysfunction of both $\mathrm{CD}^{+}$and $\mathrm{CD}^{+} \mathrm{T}$ cells, which may have been one of the reasons for the rapid tumor progression. However, transcriptional profiling should be performed to further reveal the exhausted status of these tumor infiltrating lymphocytes.

\section{Adoptively transferred TAA-specific CTLs were suppressed and failed to control tumor progression}

Adoptively transferred in-vitro activated $\mathrm{CD} 45.1^{+}$ $\mathrm{HBC}_{93-100^{-}}$specific CTLs from $\mathrm{HBC}_{93-100}$ TCR tg mice were found to be mainly located in tumor stromal regions (Fig. 6a-b). Numerous $\mathrm{PD}-1^{+}$cells as well as PD-L1 ${ }^{+}$and PD-L2 ${ }^{+}$cells were found in the stroma or tumor mass (Fig. 6b). The CTLs, at the time of adoptive transfer, expressed nearly no PD-1 or TIGIT but high level of LAG-3 (Fig. 6c) and then expressed higher levels of PD-1 and TIGIT when entering HCC TME (Fig. 6c-d, see Additional file 6: Figure S5A-C). These adoptively transferred CTLs failed to control tumor progression (Fig. 6e) even in combination with anti-PD-1 treatment (Fig. 6f), suggesting that there are regulatory cues other than PD-1 signaling contributing to the unresponsiveness of these TAA-specific CTLs. More investigations are needed to further dissect the roles of each immune checkpoint in regulation of functions and survival of endogenous and adoptively transferred TAA-specific CTLs in this model.

\section{Accumulation of immunosuppressive cell populations in Akt1/N-Ras-induced HCC-bearing mice}

Myeloid cells including TAMs and MDSCs are critical for tumor progression. We therefore analyzed the cell number of myeloid cells in the tumor and in the spleen of tumor-bearing mice and compared them with the cell number in normal control mice. Macrophages were quite abundant in tumor tissues, nearly as enriched as
Kupffer cells in liver tissues of normal mice (Fig. 7a). Splenic macrophages did not increase in tumor-bearing mice (Fig. 7a) whereas granulocytic MDCSs increased in the spleens of tumor-bearing mice (Fig. 7b). Both granulocytic and monocytic MDCSs were enriched in the tumor tissues in comparison to the normal liver tissues (Fig. 7b, c). When activated CTLs were re-stimulated and co-cultured with FACSorted macrophages or MDSCs from tumor tissues, their proliferation was severely affected by the two types of myeloid cells. The tumor-associated MDSCs inhibited T-cell proliferation at a very low myeloid/T ratio, suggesting a stronger immunosuppressive capability of MDSCs than that of TAMs (Fig. 7d, e). In addition to the myeloid cell population, there were also regulatory $\mathrm{T}$ cells (Treg) found in the HCC TCM, which may also have contributed to the immunosuppression in the TME (see Additional file 7: Figure S6A-B). The percentage of intratumoral Treg among the $\mathrm{CD} 4^{+} \mathrm{T}$-cell population was similar to that in the splenic compartment. Interestingly, the ratio of $\mathrm{CD}^{+} \mathrm{T}$ versus $\mathrm{CD}^{+} \mathrm{T}$ cells in the tumor was higher than in the spleen, implying that the HCC TME preferentially attracted $\mathrm{CD} 8^{+} \mathrm{T}$ cells but suppressed their effector functions efficiently to ensure the growth of cancer cells [17]. The spontaneous HCC mouse model we developed could serve as a useful tool to address the kinetics and mechanisms of immune cell migration and cell-cell interaction during $\mathrm{HCC}$ progression, providing useful information for development of therapeutic strategies for HCC treatment.

\section{Discussion}

In the present study, we found that macrophages, earlier than MDSCs or lymphocytes, entered the fatty change tissues in the liver upon HCC induction. Studies in non-alcoholic fatty liver disease (NAFLD) and non-alcoholic steatohepatitis (NASH) have shown that steatosis or accumulated free fatty acids caused death of hepatocytes [18]. The release of danger-associated molecular pattern (DAMPs) or apoptotic hepatocytes could activate non-parenchymal cell populations e.g. Kupffer cells and hepatic stellate cells and drive them to produce cytokines, chemokines, and reactive oxygen species (ROS) in the local microenvironment to drive repair processes, but could possibly trigger recruitment and differentiation of immune cells into liver tissue and induce chronic inflammation [19-21]. NFK-B and STAT3 signaling pathways were shown to be the key players connecting chronic inflammation and hepatocarcinogenesis [21].

It is very likely that activation of the Akt pathway in hepatocytes in this model recapitulates aberrant lipid metabolism during NAFLD, resulting in accumulation of free fatty acids and death of hepatocytes, subsequently 


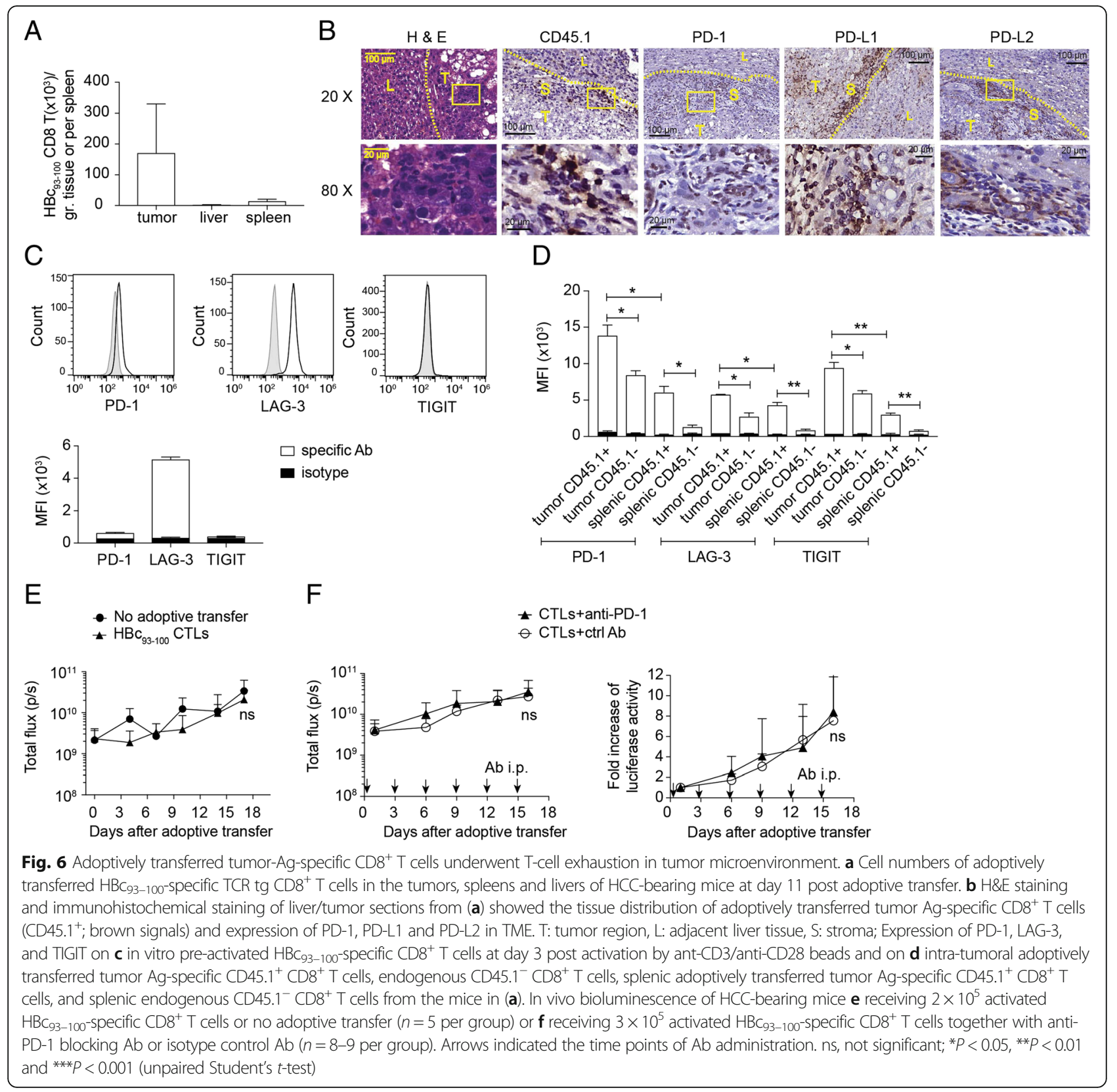

activating liver resident cells and immigratory immune cells to initiate chronic hepatitis and further liver cancer. The macrophages in the steatosis and dysplasia lesions found after activation of the Akt pathway in this model are most likely to be monocytic in origin, recruited to the inflamed liver through the CCR2-CCL2 axis, CCL1-CCR8 axis, interaction between ICAM-1 and CD44, or sphingosine 1-phosphate receptor 2/3-mediated trafficking. Although it has been shown that Akt and N-Ras co-activation could rapidly increase proliferation and angiogenesis of HCC cells via mTORC1, FOXM1/SKP2, and c-Myc pathways [7], we still could not exclude that early recruitment of the macrophages into fatty change lesions of the Akt1/N-Ras-induced HCC contributes to the HCC progression. The blockade of monocytes into fatty change lesion using a pharmacological CCR2 antagonist in this model may assist to tackle the above question [22]. It has been shown that hepatocarcinogenesis induced by AKT/ c-Met activation was totally abolished in conditional fatty acid synthase (FASN) knockout mice, suggesting an important role of lipogenesis in HCC progression in this model. Whether the lipogenesis per se or the chronic inflammation induced by the release of free fatty acids due to the lipogenesis contributes to the HCC progression in the Akt1/N-Ras-induced HCC mouse model can be further addressed using FASN inhibitors, ROS inhibitors, or 


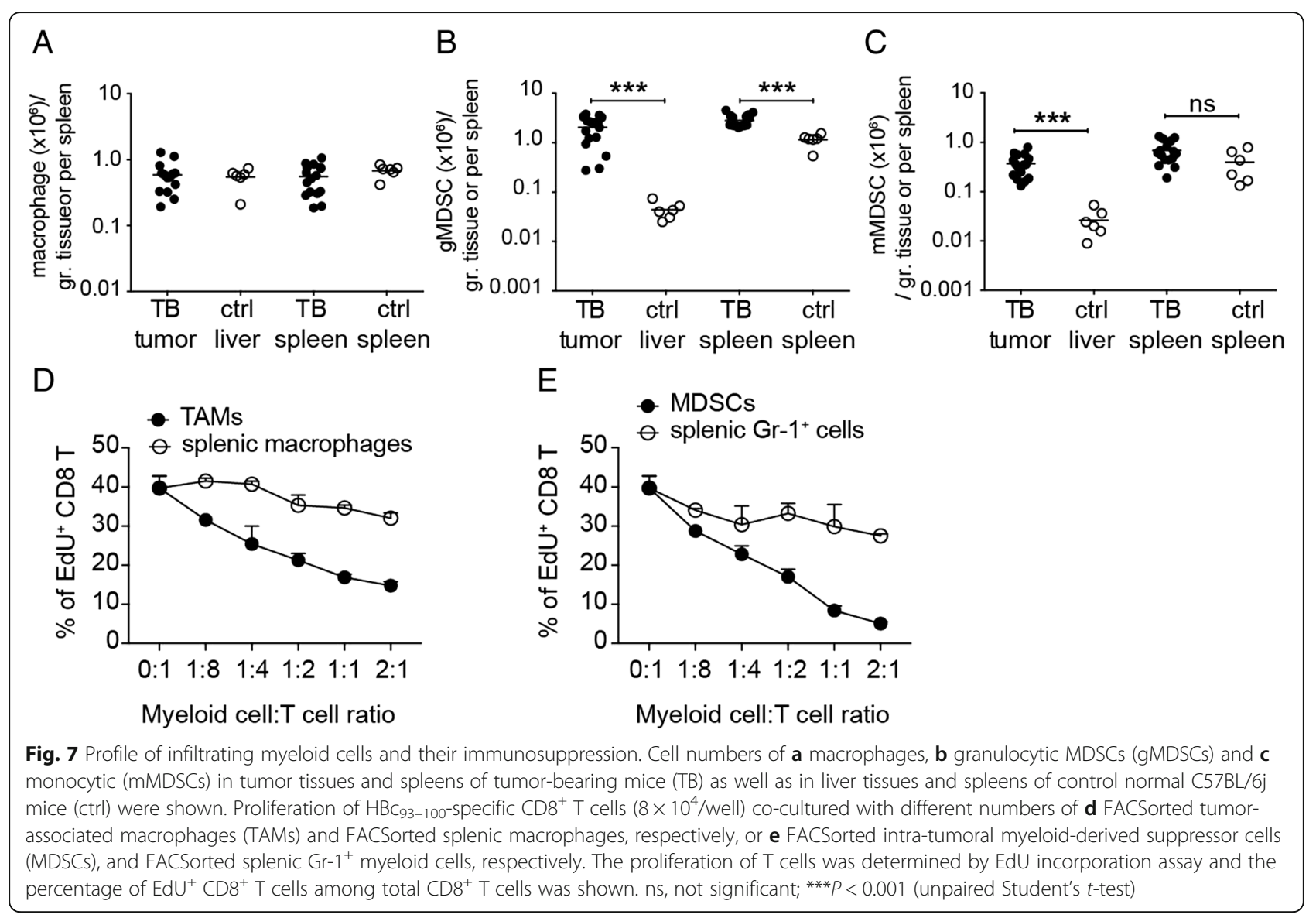

genetically modified mouse strains. The later appearance of MDSCs in the tumor excludes a major role of MDSCs in the initiation of hepatocarcinogenesis in this model. MDSCs have been shown to play important roles in the suppression of effector $\mathrm{T}$ cells and in the promotion of Treg response in various types of cancer patients including HCC patients [23-25].

Human HCC can present in several different subtypes grossly including nodular, massive, and diffuse/infiltrative tumors [26, 27]. In this Akt1/N-Ras-induced mouse model, we observed two different subtypes of HCC induced after HDI of the same three plasmids. In diffuse HCC, the cancer cells develop at the very beginning after induction and proliferate vigorously, which was evident from the high percentage of tumor cells expressing Ki-67. There were very few Ki-67-positive hepatocytes in fatty change lesions. It took a longer time to develop nodular HCC from fatty change lesions after induction. One of the possible and reasonable explanations for this phenomenon is that the in vivo transduction rate of HDI may vary in individual mice. The number of initially transduced hepatocytes after HDI may be more in the diffuse HCC group than in nodular HCC group, resulting in rapid disease progression in the diffuse group. It has been shown in the HBV mouse model that a high dose of plasmid in HDI would induce intracellular innate immune responses and subsequently affect the persistence rate of HBV and generation of an adaptive immune response against HBV [28]. Therefore, the plasmid doses in HDI may affect the integration efficiency of the sleeping beauty transposon, which could lead to differential tumor progression in this Akt1/N-Ras HCC mouse model. Liver regeneration was found to enhance growth or recurrence of HCC $[29,30]$. Because HDI per se induces hepatocytes damage during the first 2 days after injection, the HDI-associated liver damage and subsequent regeneration may accelerate tumorigenesis of Akt1/N-Rastransformed hepatocytes. The degree of hepatocyte damage induced by HDI may vary in each mouse, resulting in both diffuse and nodular types of HCC in this model.

There were fewer stroma cells found around diffuse tumors, probably due to the rapid disease progression in the diffuse group, resulting in insufficient time for the development of chronic inflammation. Conversely, we first observed fatty changes in the liver of mice receiving HDI and simultaneously, macrophages were recruited to the dysplasia area and were probably activated by the dead hepatocytes to release cytokines and chemokines, which would mediate the recruitment and activation of stroma cells and immune cells to further support the development of nodular carcinoma. This process mimics the 
inflammatory hepatocarcinogenesis induced by NASH $[18,20]$. The two subtypes of HCCs developed in the Akt1/N-Ras HCC mouse model could be easily distinguished based on the pattern of in vivo bioluminescence, and therefore are useful in studies characterizing differences in immunological features between nodular HCCs and diffuse $\mathrm{HCCs}$ and also for development of therapeutic strategies for treatment of the two subtypes of HCCs.

A recent study on the immune landscape of cancers showed that HCC belongs to the lymphocyte-deficient subtype with high M2 macrophage and suppressive Th1 responses [31]. We indeed observed a large amount of suppressive macrophages infiltrating in the Akt1/N-Ras-induced HCC tissue and impairment of CTL responses against the tumor. The endogenous or adoptively transferred TAA-specific $\mathrm{CD}^{+} \mathrm{T}$ cells were retained mainly in the stroma and showed exhausted-like phenotypes. Our finding suggests that overcoming the immunosuppressive TME of HCC is critical for the development of immunotherapy targeting HCC. Recently, immune checkpoint inhibitors and T-cell based therapy are being investigated vigorously for the treatment of various cancers. Treatment of cancer patients with anti-PD-1 has achieved $10-30 \%$ responsive rate and around $70 \%$ disease control rate in HCC patients [32]. The expression of immune checkpoints other than PD-1 on CTLs in the HCC TME was found in our study and in previous reports [33-37]. The expression of surrogate tumor Ags and a convenient method for monitoring the tumor progression and for detection and analysis of TAA-specific T-cell responses, as illustrated in the present study, make the Akt1/N-Ras induced HCC mouse model we developed a suitable preclinical model for examination of immune checkpoint inhibitors and cell-based immunotherapy for HCC treatment.

\section{Conclusions}

We have generated and characterized a novel Akt1/ $\mathrm{N}$-Ras-induced HCC mouse model which enables researchers to monitor tumor growth non-invasively. The tumor progression in this HCC model is more rapid than in most of the chemically induced models and GEMs; based on measurement of luciferase activity using IVIS, tumors size could be estimated for grading tumor progression. The expression of surrogate tumor Ags in cancer cells in the model enables the researchers to elucidate crosstalk between TAA-specific $\mathrm{T}$ cells and stromal cells, and the underlying mechanisms governing immunosuppression in the HCC TME. We illustrated the induction of TAA-specific T-cell responses and T-cell exhaustion occurring in liver cancer in our study, suggesting that the Akt1/N-Ras-induced HCC mouse model we developed is a suitable preclinical model for examination of immune checkpoint inhibitors and cell-based immunotherapy for HCC treatment.

\section{Additional files}

Additional file 1: Table S1. List of antibodies used in
immunohistochemistry and in flow cytometry. (PDF $37 \mathrm{~kb}$ )

Additional file 2: Figure S1. Immune cell profiling in the liver or tumor tissues from mice receiving HDI of pKT2/CLP-AKT, pT/Caggs-NRASV12 and PCMV(CAT)T7-SB100. (PDF $627 \mathrm{~kb}$ )

Additional file 3: Figure S2. Characterization of OVA257-264-specific CTLs in HCC tumor microenvironment. (PDF $367 \mathrm{~kb}$ )

Additional file 4: Figure S3. The expression of immune checkpoints on CD8 $+\mathrm{T}$ cells and CD4 $+\mathrm{T}$ cells from mice receiving HDI of pKT2/ CLP-AKT-Ags-LUC, pT/Caggs-NRASV12 and pCMV(CAT)T7-SB100. (PDF $313 \mathrm{~kb})$

Additional file 5: Figure S4. Proliferation and cytokine production of intra-tumoral and splenic CD8+ and CD4+ T cells after re-stimulation. (PDF 275 kb)

Additional file 6: Figure S5. The expression of immune checkpoints on adoptively transferred TAA-specific CD8 ${ }^{+} \mathrm{T}$ cells. (PDF $163 \mathrm{~kb}$ )

Additional file 7: Figure S6. Lymphocyte populations in HCC tumor microenvironment. (PDF $200 \mathrm{~kb}$ )

\section{Abbreviations}

Ag: Antigen; DPBS: Dulbecco Phosphate Buffered Saline; HBcAg: Hepatitis B core antigen; HBsAg: Hepatitis B surface antigen; HCC: Hepatocellular carcinoma; HDI: Hydrodynamic injection; MDSC: Myeloid-derived suppressor cell; MHC: Major histocomplexicity; N-Ras: Neuroblastoma Ras; ORF: Open reading frame; OVA: Ovalbumin; TAA: Tumor-associated antigen; TAM: Tumor-associated macrophage; TCR: T cell receptor; tg: transgenic; TIL: Tumor infiltrating leukocytes; TME: Tumor microenvironment; Treg: Regulatory T cells

\section{Acknowledgements}

We thank Core Instrument Center of NHRI to provide services for FACSorting and histological/pathological examinations and Laboratory Animal Center of NHRI for the animal management. We also thank Dr. Francis V. Chisari and Dr. Masanori Isogawa (The Scripps Institute, La Jolla) for providing the $\mathrm{HBC}_{93-100}$-specific TCR $\operatorname{tg}$ mice.

\section{Funding}

The work was supported by grants from NHRI (MG-106-PP-15 and MG-107PP-13) and from Ministry of Science and technology (MOST 104-2320-B-400 -017-MY3) to Li-Rung Huang and from Chang Gung Memorial Hospital to Ruey-Shyang Soong (CMRPG2F0481).

\section{Availability of data and materials}

The datasets used and/or analyzed during the current study are available from the corresponding author on reasonable request.

\section{Authors' contributions}

YTL, CYP and YHC performed the experiments. TCT, RSS, THC, JHK and LRH designed the research. $\mathrm{LRH}, \mathrm{SFH}, \mathrm{JHK}$ and THC wrote the manuscript. YTL, CYP and LRH analyzed the data. SFH performed pathology examination. All authors read and approved the final manuscript.

\section{Ethics approval}

The mice used in this study were maintained and treated according to the animal protocols (NHRI-IACUC-104048-A, NHRI-IACUC-106108-A and NHRIIACUC-107073) proved by NHRI IACUC.

Consent for publication

Not applicable.

Competing interests

The authors declare that they have no competing interests.

\section{Publisher's Note}

Springer Nature remains neutral with regard to jurisdictional claims in published maps and institutional affiliations. 


\section{Author details}

Institute of Molecular and Genomic Medicine, National Health Research Institutes, No.35, Keyan Road, Zhunan Town, Miaoli County 350, Taiwan. ${ }^{2}$ Division of Gastroenterology and Hepatology, Department of Internal Medicine, National Taiwan University Hospital, Taipei, Taiwan. ${ }^{3}$ Hepatitis Research Center, National Taiwan University, National Taiwan University Hospital, Taipei, Taiwan. ${ }^{4}$ Department of General Surgery, Chang Gung Memorial Hospital, Keelung, Taiwan. ${ }^{5}$ College of Medicine, Chang Gung University, Taoyuan, Taiwan. ${ }^{6}$ Immunology Research Center, National Health Research Institutes, Miaoli, Taiwan. ${ }^{7}$ Graduate Institute of Clinical Medicine, National Taiwan University, Taipei, Taiwan. ${ }^{8}$ Department of Medical Research, National Taiwan University, National Taiwan University Hospital, Taipei, Taiwan.

\section{Received: 28 August 2018 Accepted: 23 November 2018} Published online: 07 December 2018

\section{References}

1. Sprinzl MF, Galle PR. Current progress in immunotherapy of hepatocellular carcinoma. J Hepatol. 2017;66(3):482-4.

2. Flecken T, Schmidt N, Hild S, Gostick E, Drognitz O, Zeiser R, Schemmer P, Bruns H, Eiermann T, Price DA, Blum HE, Neumann-Haefelin C, Thimme R. Immunodominance and functional alterations of tumor-associated antigenspecific CD8+ T-cell responses in hepatocellular carcinoma. Hepatology. 2014;59(4):1415-26.

3. Santos NP, Colaco AA, Oliveira PA. Animal models as a tool in hepatocellular carcinoma research: a review. Tumour Biol. 2017;39(3): 1010428317695923

4. Heindryckx F, Colle I, Van Vlierberghe H. Experimental mouse models for hepatocellular carcinoma research. Int J Exp Pathol. 2009:90(4):367-86.

5. Huang LR, Wu HL, Chen PJ, Chen DS. An immunocompetent mouse model for the tolerance of human chronic hepatitis B virus infection. Proc Natl Acad Sci U S A. 2006:103(47):17862-7.

6. Chen X, Calvisi DF. Hydrodynamic transfection for generation of novel mouse models for liver cancer research. Am J Pathol. 2014;184(4):912-23.

7. Ho C, Wang C, Mattu S, Destefanis G, Ladu S, Delogu S, Armbruster J, Fan L, Lee SA, Jiang L, Dombrowski F, Evert M, Chen X, Calvisi DF. AKT (v-akt murine thymoma viral oncogene homolog 1) and N-Ras (neuroblastoma ras viral oncogene homolog) coactivation in the mouse liver promotes rapid carcinogenesis by way of mTOR (mammalian target of rapamycin complex 1), FOXM1 (forkhead box M1)/SKP2, and c-Myc pathways. Hepatology. 2012; 55(3):833-45.

8. Stauffer JK, Scarzello AJ, Andersen JB, De Kluyver RL, Back TC, Weiss JM, Thorgeirsson SS, Wiltrout RH. Coactivation of AKT and beta-catenin in mice rapidly induces formation of lipogenic liver tumors. Cancer Res. 2011;71(7):2718-27.

9. Calvisi DF, Wang C, Ho C, Ladu S, Lee SA, Mattu S, Destefanis G, Delogu S, Zimmermann A, Ericsson J, Brozzetti S, Staniscia T, Chen X, Dombrowski F, Evert M. Increased lipogenesis, induced by AKT-mTORC1-RPS6 signaling, promotes development of human hepatocellular carcinoma. Gastroenterology. 2011;140(3):1071-83.

10. Kang TW, Yevsa T, Woller N, Hoenicke L, Wuestefeld T, Dauch D, Hohmeyer A, Gereke M, Rudalska R, Potapova A, Iken M, Vucur M, Weiss S, Heikenwalder M, Khan S, Gil J, Bruder D, Manns M, Schirmacher P, Tacke F, Ott M, Luedde T, Longerich T, Kubicka S, Zender L. Senescence surveillance of pre-malignant hepatocytes limits liver cancer development. Nature. 2011; 479(7374):547-51.

11. Wang C, Cigliano A, Delogu S, Armbruster J, Dombrowski F, Evert M, Chen X, Calvisi DF. Functional crosstalk between AKT/mTOR and Ras/MAPK pathways in hepatocarcinogenesis: implications for the treatment of human liver cancer. Cell Cycle. 2013;12(13):1999-2010.

12. Isogawa M, Chung J, Murata Y, Kakimi K, Chisari FV. CD40 activation rescues antiviral CD8(+) T cells from PD-1-mediated exhaustion. PLoS Pathog. 2013; 9(7):e1003490

13. Mates L, Chuah MK, Belay E, Jerchow B, Manoj N, Acosta-Sanchez A, Grzela DP, Schmitt A, Becker K, Matrai J, Ma L, Samara-Kuko E, Gysemans C, Pryputniewicz D, Miskey C, Fletcher B, VandenDriessche T, Ivics Z, Izsvak Z. Molecular evolution of a novel hyperactive sleeping beauty transposase enables robust stable gene transfer in vertebrates. Nat Genet. 2009;41(6):753-61.

14. Wiesner SM, Decker SA, Larson JD, Ericson K, Forster C, Gallardo JL, Long C, Demorest ZL, Zamora EA, Low WC, SantaCruz K, Largaespada DA, Ohlfest JR.
De novo induction of genetically engineered brain tumors in mice using plasmid DNA. Cancer Res. 2009:69(2):431-9.

15. Jian SL, Chen WW, Su YC, Su YW, Chuang TH, Hsu SC, Huang LR. Glycolysis regulates the expansion of myeloid-derived suppressor cells in tumorbearing hosts through prevention of ROS-mediated apoptosis. Cell Death Dis. 2017:8(5):e2779.

16. Finkin S, Yuan D, Stein I, Taniguchi K, Weber A, Unger K, Browning JL, Goossens N, Nakagawa S, Gunasekaran G, Schwartz ME, Kobayashi M, Kumada H, Berger M, Pappo O, Rajewsky K, Hoshida Y, Karin M, Heikenwalder M, Ben-Neriah Y, Pikarsky E. Ectopic lymphoid structures function as microniches for tumor progenitor cells in hepatocellular carcinoma. Nat Immunol. 2015;16(12):1235-44

17. Zheng C, Zheng L, Yoo JK, Guo H, Zhang Y, Guo X, Kang B, Hu R, Huang JY, Zhang Q, Liu Z, Dong M, Hu X, Ouyang W, Peng J, Zhang Z. Landscape of infiltrating $T$ cells in liver Cancer revealed by single-cell sequencing. Cell. 2017;169(7):1342-56 e1316.

18. Malhi H, Gores GJ. Molecular mechanisms of lipotoxicity in nonalcoholic fatty liver disease. Semin Liver Dis. 2008;28(4):360-9.

19. Malhi H, Guicciardi ME, Gores GJ. Hepatocyte death: a clear and present danger. Physiol Rev. 2010;90(3):1165-94.

20. Pellicoro A, Ramachandran P, Iredale JP, Fallowfield JA. Liver fibrosis and repair: immune regulation of wound healing in a solid organ. Nat Rev Immunol. 2014;14(3):181-94.

21. $Y u$ LX, Ling $Y$, Wang HY. Role of nonresolving inflammation in hepatocellular carcinoma development and progression. NPJ Precis Oncol. 2018:2(1):6.

22. Weisberg SP, Hunter D, Huber R, Lemieux J, Slaymaker S, Vaddi K, Charo I, Leibel RL, Ferrante AW Jr. CCR2 modulates inflammatory and metabolic effects of high-fat feeding. J Clin Invest. 2006;116(1):115-24.

23. Hoechst B, Ormandy LA, Ballmaier M, Lehner F, Kruger C, Manns MP, Greten TF, Korangy F. A new population of myeloid-derived suppressor cells in hepatocellular carcinoma patients induces CD4(+)CD25(+)Foxp3(+) T cells. Gastroenterology. 2008;135(1):234-43

24. Kalathil S, Lugade AA, Miller A, lyer R, Thanavala Y. Higher frequencies of GARP(+)CTLA-4(+)Foxp3(+) T regulatory cells and myeloid-derived suppressor cells in hepatocellular carcinoma patients are associated with impaired T-cell functionality. Cancer Res. 2013;73(8):2435-44.

25. Alfaro C, Teijeira A, Onate C, Perez G, Sanmamed MF, Andueza MP, Alignani D, Labiano S, Azpilikueta A, Rodriguez-Paulete A, Garasa S, Fusco JP, Aznar A, Inoges S, De Pizzol M, Allegretti M, Medina-Echeverz J, Berraondo P, Perez-Gracia JL, Melero I. Tumor-produced Interleukin-8 attracts human myeloid-derived suppressor cells and elicits extrusion of neutrophil extracellular traps (NETs). Clin Cancer Res. 2016;22(15):3924-36.

26. Okuda K, Noguchi T, Kubo Y, Shimokawa Y, Kojiro M, Nakashima T. A clinical and pathological study of diffuse type hepatocellular carcinoma. Liver. 1981;1(4):280-9.

27. Trevisani F, Caraceni P, Bernardi M, D'Intino PE, Arienti V, Amorati $P$, Stefanini GF, Grazi G, Mazziotti A, Fornale L, et al. Gross pathologic types of hepatocellular carcinoma in Italian patients. Relationship with demographic, environmental, and clinical factors. Cancer. 1993;72(5):1557-63.

28. Li L, Li S, Zhou Y, Yang L, Zhou D, Yang Y, Lu M, Yang D, Song J. The dose of HBV genome contained plasmid has a great impact on HBV persistence in hydrodynamic injection mouse model. Virol J. 2017;14(1):205.

29. Shi JH, Huitfeldt HS, Suo ZH, Line PD. Growth of hepatocellular carcinoma in the regenerating liver. Liver Transpl. 2011;17(7):866-74.

30. Coban Z, Barton MC. Integrative genomics: liver regeneration and hepatocellular carcinoma. J Cell Biochem. 2012;113(7):2179-84.

31. Thorsson V, Gibbs DL, Brown SD, Wolf D, Bortone DS, Ou Yang TH, PortaPardo E, Gao GF, Plaisier CL, Eddy JA, Ziv E, Culhane AC, Paull EO, Sivakumar IKA, Gentles AJ, Malhotra R, Farshidfar F, Colaprico A, Parker JS, Mose LE, Vo NS, Liu J, Liu Y, Rader J, Dhankani V, Reynolds SM, Bowlby R, Califano A, Cherniack AD, Anastassiou D, Bedognetti D, Rao A, Chen K, Krasnitz A, Hu H, Malta TM, Noushmehr H, Pedamallu CS, Bullman S, Ojesina Al, Lamb A, Zhou W, Shen H, Choueiri TK, Weinstein JN, Guinney J, Saltz J, Holt RA, Rabkin CE, Cancer Genome Atlas Research N, Lazar AJ, Serody JS, Demicco $E G$, Disis ML, Vincent BG, Shmulevich L. The immune landscape of Cancer. Immunity. 2018;48(4):812-30 e814.

32. Kudo M. Immune Checkpoint Inhibition in Hepatocellular Carcinoma: Basics and Ongoing Clinical Trials. Oncology. 2017;92(Suppl 1):50-62.

33. Han $Y$, Chen $Z$, Yang $Y$, Jiang $Z$, Gu $Y$, Liu $Y$, Lin $C$, Pan $Z, Y u ~ Y$, Jiang M, Zhou W, Cao X. Human CD14+ CTLA-4+ regulatory dendritic cells 
suppress T-cell response by cytotoxic T-lymphocyte antigen-4dependent IL-10 and indoleamine-2,3-dioxygenase production in hepatocellular carcinoma. Hepatology. 2014;59(2):567-79.

34. Shi F, Shi M, Zeng Z, Qi RZ, Liu ZW, Zhang JY, Yang YP, Tien P, Wang FS. PD-1 and PD-L1 upregulation promotes CD8(+) T-cell apoptosis and postoperative recurrence in hepatocellular carcinoma patients. Int J Cancer. 2011;128(4):887-96.

35. Li FJ, Zhang Y, Jin GX, Yao L, Wu DQ. Expression of LAG-3 is coincident with the impaired effector function of HBV-specific CD8(+) T cell in HCC patients. Immunol Lett. 2013;150(1-2):116-22.

36. Li H, Wu K, Tao K, Chen L, Zheng Q, Lu X, Liu J, Shi L, Liu C, Wang G, Zou W. Tim-3/galectin-9 signaling pathway mediates T-cell dysfunction and predicts poor prognosis in patients with hepatitis B virus-associated hepatocellular carcinoma. Hepatology. 2012;56(4):1342-51.

37. Xu F, Jin T, Zhu Y, Dai C. Immune checkpoint therapy in liver cancer. J Exp Clin Cancer Res. 2018;37(1):110.

Ready to submit your research? Choose BMC and benefit from:

- fast, convenient online submission

- thorough peer review by experienced researchers in your field

- rapid publication on acceptance

- support for research data, including large and complex data types

- gold Open Access which fosters wider collaboration and increased citations

- maximum visibility for your research: over $100 \mathrm{M}$ website views per year

At $\mathrm{BMC}$, research is always in progress.

Learn more biomedcentral.com/submissions 